\title{
RELAÇÃO DOS PROCESSOS EROSIVOS LINEARES COM OS ATRIBUTOS DO RELEVO NO MUNICÍPIO DE UNISTALDA - RS \\ LIST OF EROSION LINEAR WITH ATTRIBUTES OF RELIEF IN MUNICIPALITY UNISTALDA - RS
}

\author{
Igor da Silva Knierin ${ }^{1}$ Romario Trentin ${ }^{1}$, Luís Eduardo de Souza Robaina ${ }^{1}$ \\ ${ }^{1}$ Universidade Federal de Santa Maria (UFSM), Santa Maria, RS, Brasil
}

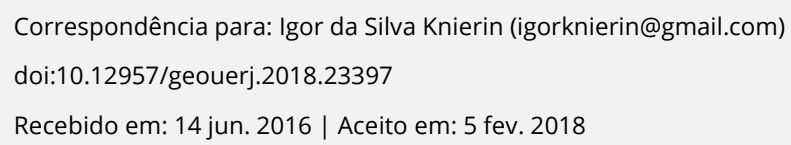

\section{RESUMO}

A degradação dos solos afeta extensas áreas na região Centro-Oeste a Oeste do Rio Grande do Sul, onde se identificam feições superficiais como processos erosivos lineares e núcleos de arenização, que desencadeiam sérios problemas ambientais. Integrado a isso, este trabalho possuiu como objetivo, o mapeamento dos processos erosivos lineares e identificar sua relação com os diferentes atributos morfométricos do relevo no município de Unistalda - RS - Brasil. Os procedimentos metodológicos se basearam na elaboração e análise de mapas temáticos dos processos erosivos lineares e do relevo, os quais foram realizados no ArcGIS® 10.1 com base em imagens de satélite ópticas e de RADAR SRTM. Desta forma, identificou-se nas áreas afetadas pela erosão dos solos como mais recorrentes, altitudes inferiores a 200 m, com a classe de 150-200 m, declividades superiores a 5\%, com a classe 5-15\%, perfis de curvatura côncavos, planos de curvatura convergentes e formas das vertentes côncavo-convergente. Frente a isso, observou-se satisfatório no presente estudo a utilização de técnicas de geoprocessamento, integradas ao SIG, com base em imagens de satélite ópticas e de RADAR SRTM, conforme validado nos trabalhos de campo.

Palavras-chave: Erosão dos Solos. Morfometria. Relevo. SIG. SRTM

\begin{abstract}
The soil degradation affects large areas in the region West and Midwest of Rio Grande do Sul, where are identified surface features as linear erosion and arenization cores, triggering serious environmental problems. Integrated with this, the work aims, the mapping of linear erosive processes and identify their relationship to the different attributes morphometric of relief in the municipality of Unistalda - RS - Brazil. The methodological procedures were performed in ArcGIS ${ }^{\circ} 10.1$ and had the base images optical satellite and RADAR SRTM. Thus, was identified in areas affected by soil erosion as most recurring, elevations below $200 \mathrm{~m}$, with the class of 150-200 m, slopes above 5\%, with the class 5-15\%, curvature profiles concave, plans curvature converging and forms of the strands concave-converging. Thus, there was satisfactory in this study the use of geoprocessing techniques, integrated with GIS, based on images optical satellite and RADAR SRTM, as validated in the field.
\end{abstract}

Keywords: Soil erosion. Morphometry. Relief. GIS. SRTM

\section{INTRODUÇÃO}

A degradação dos solos afeta extensas áreas, tanto nos meios rurais como urbanos em diferentes regiões do Globo, o qual segundo Cerri et al. (1997) e Guerra (2014) deve corresponder ao processo geológico que mais afeta extensas áreas no território brasileiro, ratificando-se no grande número de profissionais dedicados ao estudo desta temática, como geólogos, geógrafos, agrônomos e pedólogos. 
Por meio da utilização de imagens de satélite ópticas, de alta resolução, se torna possível monitorar e mapear os processos erosivos, permitindo análises mais precisas, bem como facilitado os trabalhos de levantamento das áreas afetadas pela erosão (SANTOS e FARIA, 2011). Além do mais, é possível a elaboração de inúmeros modelos para o estudo de áreas com potencial erosivo, adotando para isso análise digital do relevo por meio de Modelos Digitais de Elevação (MDEs) (VALERIANO, 2008; SILVEIRA et al., 2014).

Desse modo, a identificação e a compreensão dos fatores desencadeantes dos processos erosivos têm sido facilitadas pelos avanços das geotecnologias, a medida em que permitem fazer avaliações temporais e pontuais, frente ao estado de degradação dos solos (CASTRO et al. 2010), como também de identificação de áreas suscetíveis ao desenvolvimento dos mesmos.

Integrado a este tema, no segmento Centro-Oeste a Oeste do Rio Grande Sul, são desenvolvidos projetos e pesquisas para o estudo das fragilidades e vulnerabilidades ambientais da área. Na região se identificam feições superficiais como processos erosivos lineares e núcleos de arenização, associados as características físico-naturais e as diferentes formas de uso e ocupação da terra, que desencadeiam sérios problemas ambientais.

Estudos dessa natureza se caracterizam a partir das contribuições de Souto (1985), Suertegaray (1987), Ab'Saber (1995), Verdum (1997), Suertegaray (1998), Suertegaray et al. (2001), De Nardin (2009), Trentin (2011), Suertegaray et al. (2012), Souza (2015) entre outros, os quais buscam investigar, em diferentes formas de abordagem, a questão da erosão linear dos solos na região, assim como os processos de arenização.

Corroborando com a importância de estudos desta temática na região, este trabalho busca contribuir e apresenta como objetivo mapear os processos erosivos lineares e identificar sua relação com os atributos morfométricos do relevo no município de Unistalda - RS. 
A área de estudo localiza-se no Brasil Meridional, na porção Centro-Oeste do Rio Grande do Sul, entre as coordenadas geográficas $54^{\circ} 59^{\prime} 18.05^{\prime \prime}$ a $55^{\circ} 19^{\prime} 17.18^{\prime \prime}$ de Longitude Oeste e $28^{\circ} 56^{\prime} 6.99^{\prime \prime}$ a $29^{\circ} 12^{\prime} 51.77^{\prime \prime}$ de Latitude Sul, de acordo com a Figura 1.

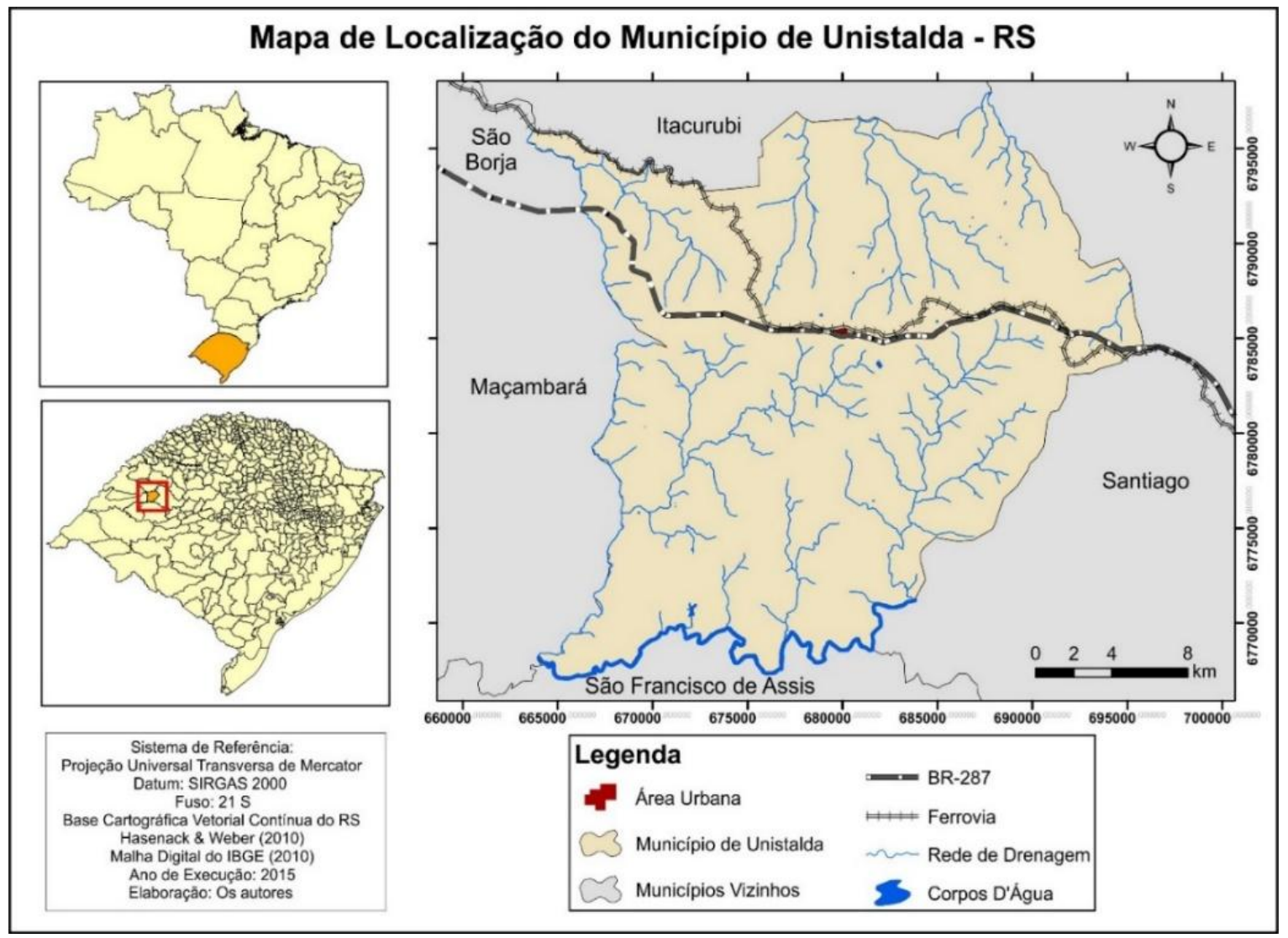

Figura 1. Mapa de localização com a rede de drenagem, área urbana e principais vias de acesso do município de Unistalda RS.

\section{PROCEDIMENTOS METODOLÓGICOS}

O desenvolvimento deste trabalho foi realizado com base no mapeamento dos processos erosivos lineares e dos atributos morfométricos do relevo para o município de Unistalda - RS, seguido pela identificação da relação dos processos erosivos lineares com os atributos morfométricos do relevo da área de estudo.

Para o mapeamento dos processos erosivos foram utilizadas imagens de satélite ópticas disponíveis no serviço Basemap - World Imagery do ArcGIS® 10.1, como também o software Google Earth Pro, 
sendo este último para análise comparativa das imagens. Desta forma, foi realizado no ArcGIS® 10.1 o mapeamento dos processos erosivos lineares na área de estudo no ano de 2015, a partir da vetorização manual, na forma de linhas, dos processos superficiais.

No estudo do relevo, foram elaborados e analisados mapas de hipsometria, declividade, perfil de curvatura, plano de curvatura e com a integração destes dois últimos, com as formas das vertentes da área de estudo.

Para a modelagem do relevo, foi utilizado como Modelo Digital de Elevação a imagem de RADAR do Shuttle Radar Topography Mission (SRTM), com resolução espacial de 90 m, obtida junto ao USGS (United States Geological Survey), a qual passou pelo processo de retificação através da ferramenta Fill disponível no módulo Spatial Analyst do ArcGIS® 10.1 .

O mapa hipsométrico foi elaborado a partir da referida base, a qual foram definidas seis classes, por meio do método de Quebras Naturais, conforme apresenta Ferreira (2014), em que os limites das classes são identificados através das rupturas naturais existentes na série de dados originais. Com base nisso, obteve-se as classes altimétricas: $<150 \mathrm{~m}, 150-200 \mathrm{~m}, 200-250 \mathrm{~m}, 250-300 \mathrm{~m}, 300-350 \mathrm{~m} \mathrm{e}$ $>350 \mathrm{~m}$.

O mapa de declividade foi elaborado com a ferramenta Slope, do módulo Spatial Analyst do ArcGIS® 10.1, e teve como base topográfica a imagem de RADAR SRTM com resolução espacial de $90 \mathrm{~m}$ retificada.

Foram adotadas quatro classes de declividades: $<2 \%, 2-5 \% 5-15 \%$ e $>15 \%$, as quais se associam ao desenvolvimento de processos superficiais e aos tipos de uso e ocupação da terra, conforme apresenta Robaina et al. (2010) adaptado do Instituto de Pesquisas Tecnológicas de São Paulo (IPT, 1981), para estudos geoambientais, de erosão linear dos solos e núcleos de arenização nas regiões Oeste e Sudoeste do Rio Grande do Sul. 
Os mapas de curvaturas das vertentes para o perfil de curvatura, plano de curvatura e, por conseguinte, de formas das vertentes, foram elaborados a partir da ferramenta Curvature, do módulo Spatial Analyst disponível no ArcGIS ${ }^{\circledR} 10.1$ e tiveram como base o MDE oriundo a imagem de RADAR SRTM, com resolução espacial de 90 m retificada.

Por meio deste processo se obteve como produto dois arquivos, um referente aos perfis de curvatura e outro aos planos de curvatura. Os perfis de curvatura foram classificados em vertentes convexas e côncavas. Enquanto os planos de curvatura foram classificados em vertentes convergentes e divergentes.

O mapa de formas das vertentes foi obtido a partir da combinação do perfil de curvatura e do plano de curvatura das vertentes da área de estudo, utilizando para isso a ferramenta Combine do módulo Spatial Analyst disponível no ArcGIS® 10.1. A partir dos resultados se obteve quatro classes para as formas das vertentes da área de estudo, identificadas em vertentes: convexo-divergente, convexoconvergente, côncavo-divergente e côncavo-convergente.

De posse do mapeamento dos processos erosivos lineares e da modelagem do relevo, executou-se o cruzamento dos layers (camadas) - dos processos erosivos lineares com as variáveis morfométricas do relevo (hipsometria, declividade, perfil de curvatura, plano de curvatura e formas das vertentes) através da ferramenta Intersect, do módulo Analysis, do ArcGIS® 10.1. Com base no produto final deste processo, foi realizado a quantificação dos atributos morfométricos do relevo nas áreas afetadas por processos erosivos lineares no município de Unistalda - RS.

Os trabalhos de campo realizados nos dias 28, 29 e 30 de outubro de 2015 permitiram a validação do estudo e análise in loco das áreas afetadas pelos processos de erosão linear e da morfologia da área de estudo. Foram percorridos estradas e caminhos em toda a extensão do estudo e realizado o registro e coleta de pontos de controle e descrição de condições que potencializavam a suscetibilidade para erosão linear dos solos. 


\section{RESULTADOS E DISCUSSÃO}

\section{Mapeamento e Caracterização dos Processos Erosivos Lineares}

No município de Unistalda - RS, são identificados processos de erosão hídrica, do tipo linear na forma de sulcos, ravinas e voçorocas, os quais localizam-se a Oeste, Sudoeste e Sul do município, em uma extensa área rural, drenada por afluentes do Rio Itu com hierarquia fluvial de até $3^{0}$ ordem e pelo Arroio Itu-Mirim com hierarquia fluvial de $5^{0}$ ordem, conforme a classificação de Strahler (1952) (Figura 2).

Os processos erosivos lineares, são identificados de duas formas características na área de estudo:

I - Processos erosivos lineares conectados à rede de drenagem.

II - Processos erosivos lineares não conectados à rede de drenagem.

Os primeiros (I) caracterizam-se por processos conectados em cabeceiras de drenagem, que ocorrem no topo de colinas e podem se estabelecer ou não nas vertentes associados a base de feições como cornijas. O segundo tipo de processo (II), por sua vez, não ocorre conectado às cabeceiras de drenagem e se distribui diretamente relacionado junto a base de morros, morrotes e/ou cornijas.

As litologias constituem-se predominantemente por arenitos, com variáveis níveis de coesão dado pelo cimento ferruginoso, além de rochas vulcânicas associadas. Quando os arenitos se apresentam com camadas cimentadas e, por consequência, mais resistentes a dissecação do relevo, constituem formas residuais de morros, morrotes ou cornijas que podem se associar aos respectivos processos de erosão. Os solos são bem desenvolvidos e arenosos, apresentam pouca diferenciação entre os horizontes e, em razão do baixo teor de ligantes indicam baixa resistência aos processos de erosão. 


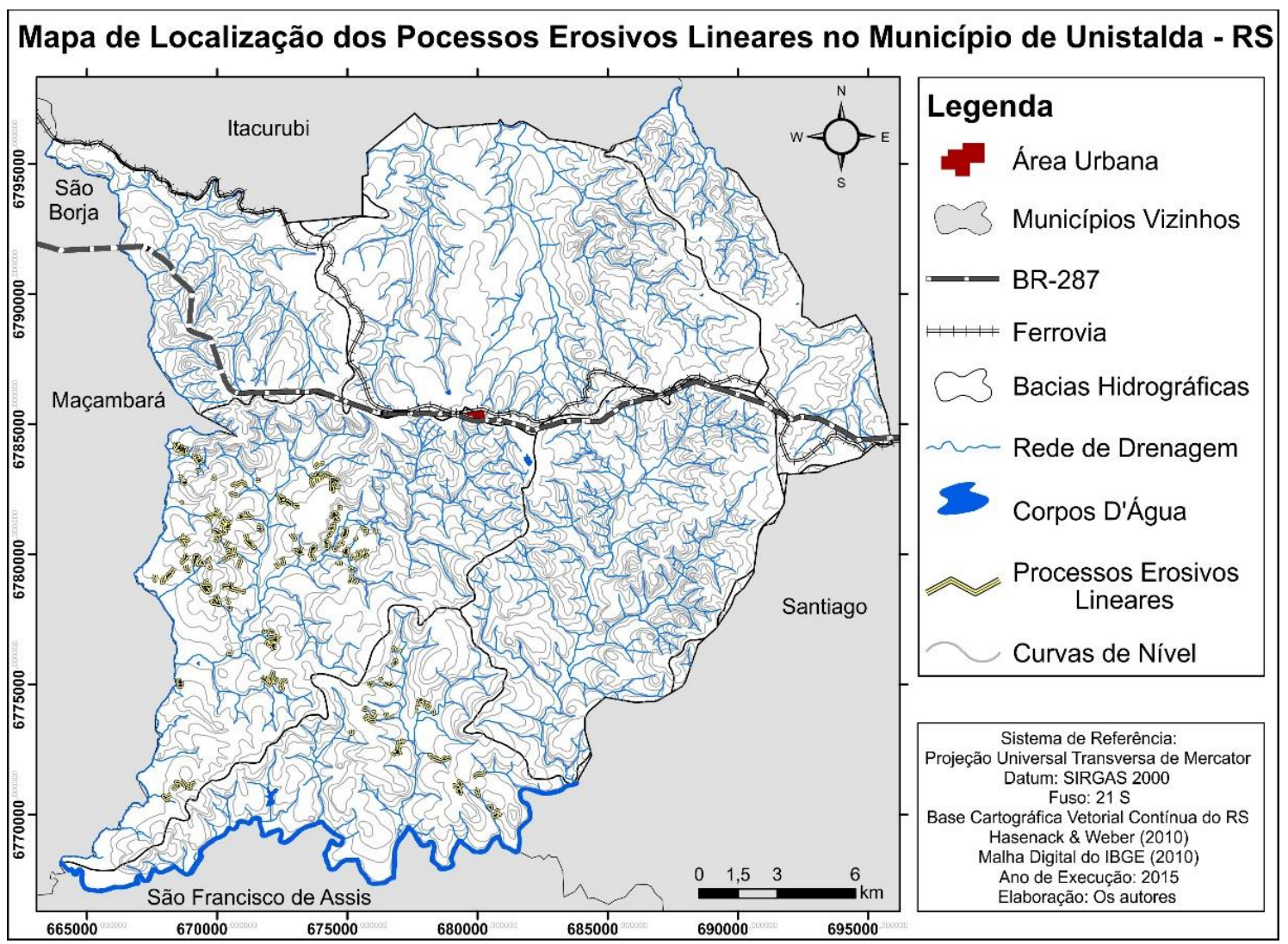

Figura 2. Mapa de localização dos processos erosivos lineares com as curvas de nível, bacias hidrográficas, rede de drenagem, principais vias de acesso e área urbana do município de Unistalda - RS.

Embora os processos erosivos sejam naturais, na qual configuram uma busca de equilíbrio da paisagem, as diferentes formas de uso e ocupação da terra, em áreas naturalmente suscetíveis aos mesmos, como litologias friáveis e solos arenosos, por exemplo, contribuem com a ocorrência e/ou intensificação dos mesmos.

\section{Morfometria do Relevo}

\section{Hipsometria}

O município de Unistalda - RS, está localizado em uma região de transição entre os compartimentos geomorfológicos do Planalto das Missões e da Depressão do Ibicuí (ROBAINA et al., 2010), apresenta altitudes que variam de cotas com 120 m a Sudoeste, junto ao Rio Itu - RS e de 426 m localizada em porção Leste do município junto ao seu limite com Santiago - RS, e dessa forma, conferindo em amplitude altimétrica de $306 \mathrm{~m}$. 
A partir da Figura 3 e da Tabela 1 pode ser visualizado a distribuição espacial e a quantificação das classes hipsométricas na área do município.

A classe de altitudes inferiores a $150 \mathrm{~m}$, cobre $6,21 \%$ da área de estudo, localizada nas porções Sudoeste e Sul do município junto ao Rio Itu e ao Arroio Itu-Mirim.

A classe de altitudes com 150-200 m, por sua vez, representa 20,09\% da área de estudo, distribuída nas porções Sul, Oeste, Norte e Noroeste do município. Observa-se o maior número de processos erosivos lineares recorrentes nesta classe, integrados aos sistemas de drenagem do Arroio Itu-Mirim e dos afluentes de até $3^{0}$ ordem do Rio Itu.

A classe de altitudes de 200-250 m, cobre maior área no município, representando $25,48 \%$ de sua área total. Marca uma faixa de transição entre os compartimentos geomorfológicos do Planalto das Missões e da Depressão do Ibicuí (ROBAINA et al., 2010).

A classe de altitudes de 250-300 m cobre 22,40\% da área de estudo, e apresenta-se espacializada na faixa Central do município, como também em direção Centro-Leste e Centro-Oeste do mesmo. Entretanto, suas maiores áreas cobrem terrenos na extensão Norte da área do município, associado a linhas de escarpas do rebordo, onde integra as porções de médio e alto curso das bacias hidrográficas, como também, associando a pontos divisores d'água e de cabeceiras de drenagem da rede fluvial. 


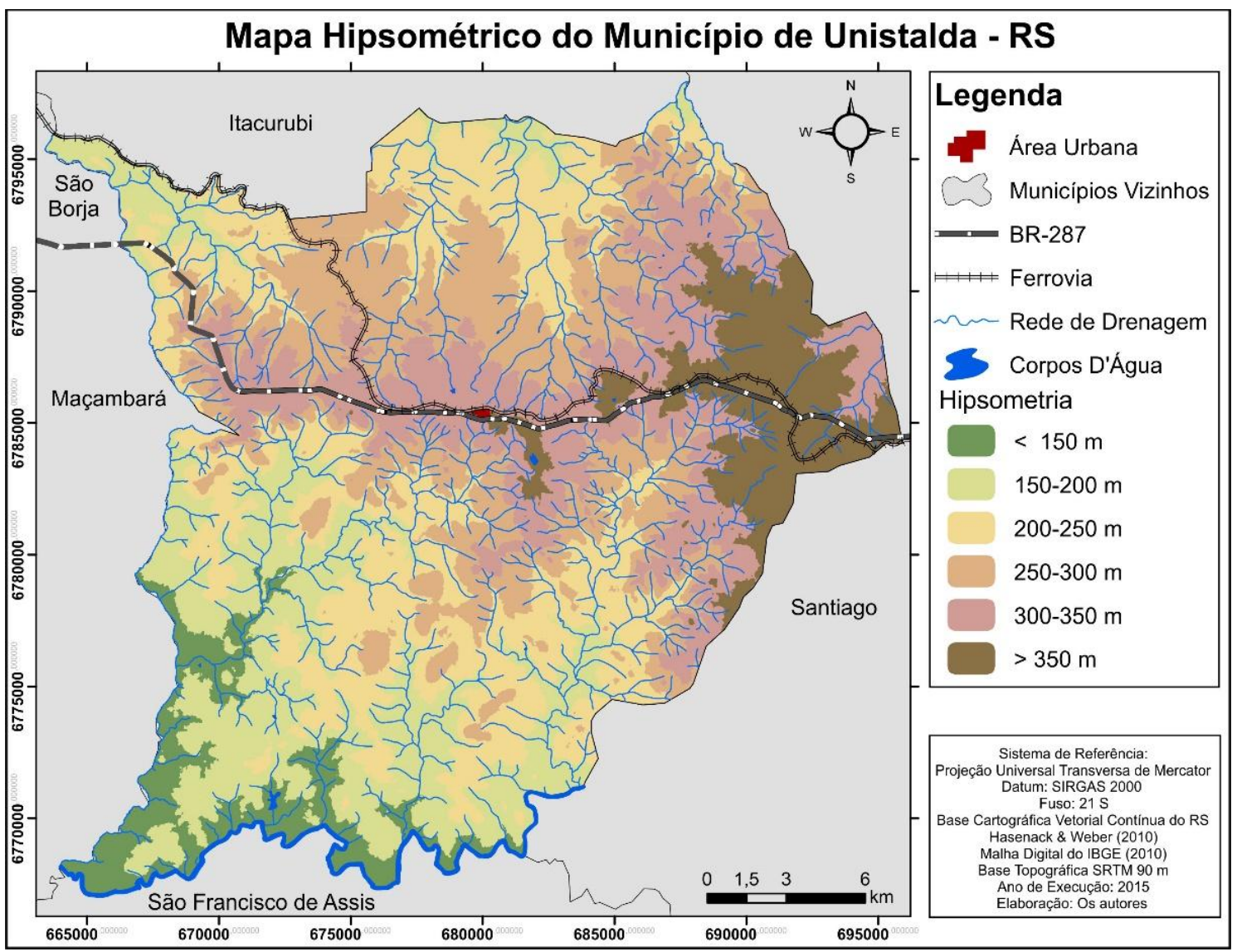

Figura 3. Mapa hipsométrico com a rede de drenagem, principais vias de acesso e área urbana do município de Unistalda RS.

\begin{tabular}{ccc}
\hline Classes Hipsométricas & Área $\mathbf{~ e m ~} \mathbf{~ k m}^{\mathbf{2}}$ & Área em \% \\
\hline$<150 \mathrm{~m}$ & 37,43 & 6,21 \\
$150-200 \mathrm{~m}$ & 120,99 & 20,09 \\
$200-250 \mathrm{~m}$ & 153,50 & 25,48 \\
$250-300 \mathrm{~m}$ & 134,90 & 22,40 \\
$300-350 \mathrm{~m}$ & 101,16 & 16,79 \\
$>350 \mathrm{~m}$ & 54,41 & 9,03 \\
\hline
\end{tabular}

Tabela 1. Quantificação das classes hipsométricas do município de Unistalda - RS.

A classe de altitudes de 300-350 m cobre 16,79\% da área do município, distribui-se de Oeste a Leste da sua área, onde individualiza as drenagens em afluentes do Rio Icamaquã ao Norte e em afluentes do Rio Itu ao Sul, configurando dessa forma uma faixa de interflúvio, como também, de nascentes dos cursos d'água nos setores de médio e alto curso das bacias hidrográficas da área de estudo. 
Por fim, a classe de altitudes superiores a $350 \mathrm{~m}$, cobre 9,03\% do município, associando-se as áreas limítrofes dos sistemas de drenagem em seus pontos divisores d'água, como também de nascentes da rede de drenagem.

\section{Declividades das Vertentes}

No município de Unistalda - RS foram analisadas quatro classes de declividades, sendo elas inferiores a $2 \%$, entre 2 e $5 \%$, entre 5 e $15 \%$ e superiores a $15 \%$, conforme representadas a partir do mapa da Figura 4 e quantificadas na Tabela 2.

As declividades inferiores a 2\%, cobrem $11,67 \%$ da área do município, as quais caracterizam-se por serem áreas planas como planícies e/ou topos de alguns morros e morrotes. Quando associadas a rede de drenagem, são predominantes os processos de inundação e deposição sedimentar, com a formação de bancos de areia, em especial, no Rio Itu, e com atividades de uso da terra com rizicultura.

A classe de declividades de 2-5\% distribui-se em $25,11 \%$ da área de estudo e correspondem as áreas de vertentes levemente onduladas, que se associam a um relevo de colinas e com tipos de usos da terra identificados predominantemente como agropastoris.

A classe de declividades distribuídas entre os 5-15\%, cobrem 52,58\%, sendo a classe de maior área no município, associada a um relevo de colinas onduladas, com declividades limítrofes para o uso de maquinário agrícola, com usos da terra, assim como na classe anterior, com atividades agropastoris. Nessa classe é onde são identificados o maior número dos processos erosivos lineares na área do município, com a formação de sulcos, ravinas e voçorocas. 


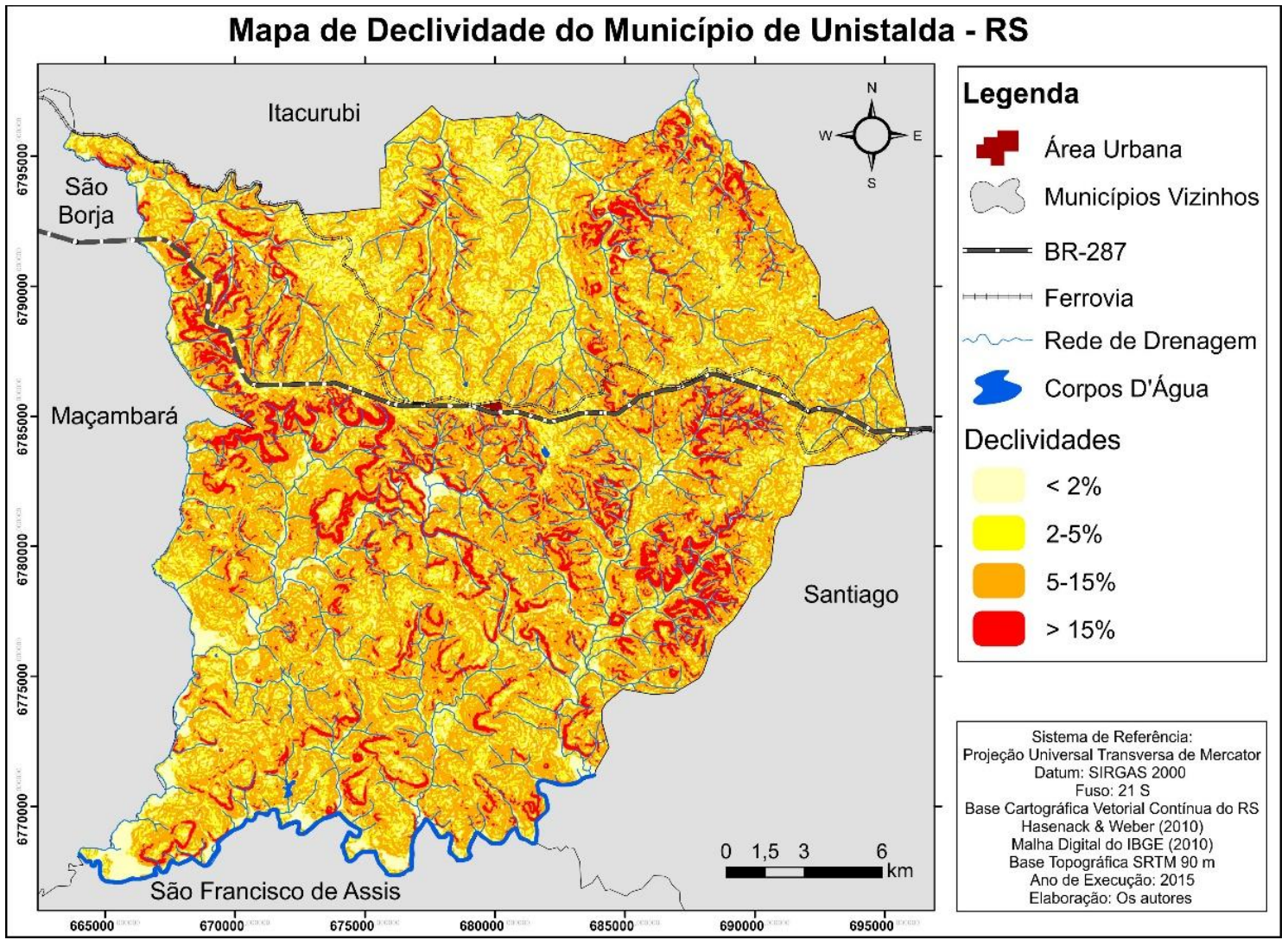

Figura 4. Mapa de Declividade com a rede de drenagem, principais vias de acesso e área urbana do município de Unistalda - RS.

\begin{tabular}{|c|c|c|}
\hline Classes de Declividade & Área em km² & Área em \% \\
\hline$<2 \%$ & 70,32 & 11,67 \\
\hline $2-5 \%$ & 151,24 & 25,11 \\
\hline $5-15 \%$ & 316,72 & 52,58 \\
\hline$>15 \%$ & 64,10 & 10,64 \\
\hline
\end{tabular}

Tabela 2. Quantificação das classes de declividade do município de Unistalda - RS. Fonte: Arquivo pessoal (2015).

Por fim, a classe de declividades superiores a 15\%, cobre 10,64\% do município, sendo a classe de menor área a qual associa-se a formas de relevo fortemente ondulado com vertentes íngremes e escarpadas de morros e morrotes, como também com a formação de linhas de quebras do relevo com cornijas. O uso da terra, apresenta-se de maneira mais restrita, nas áreas de vertentes muito íngremes como morros e morrotes. 


\section{Curvaturas das Vertentes}

Para o município de Unistalda - RS foram analisados os perfis e os planos de curvaturas das vertentes. Os perfis de curvatura, classificados em vertentes convexas e côncavas podem ser visualizadas de acordo com a Figura 5 e na Tabela 3, com a distribuição espacial e a quantificação das classes na área de estudo.

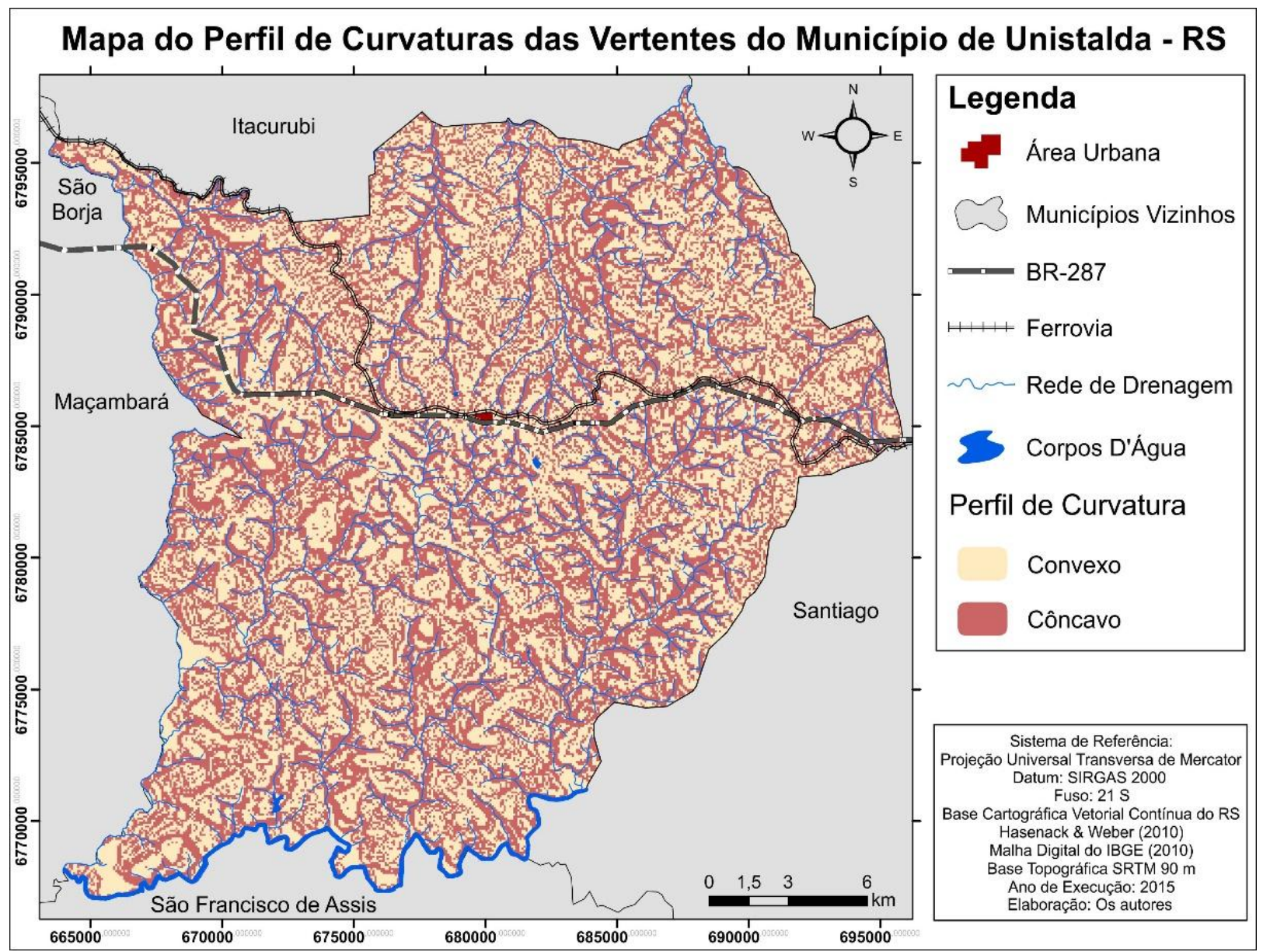

Figura 5. Mapa do perfil de curvatura das vertentes com a rede de drenagem, principais vias de acesso e área urbana do município de Unistalda - RS

\begin{tabular}{ccc}
\hline Perfil de Curvatura & Área $\mathbf{~ e m ~} \mathbf{k m}^{\mathbf{2}}$ & Área em \% \\
\hline Convexo & 301,32 & 50,02 \\
Côncavo & 301,06 & 49,98 \\
\hline
\end{tabular}

Tabela 3. Quantificação do perfil de curvatura das vertentes do município de Unistalda - RS.

Fonte : Arquivo pessoal 2015

As vertentes convexas cobrem 50,02\% da área do município, enquanto as vertentes côncavas, representam 49,98\% da mesma. Os perfis de curvatura permitem indicar de maneira geral em qual 
segmento da vertente podem atuar as maiores energias dos fluxos superficiais e dessa forma, no ponto condicionado ao relevo, em que a ação erosiva é mais suscetível.

Para o plano de curvatura, foram classificadas as vertentes em divergentes e convergentes, conforme podem ser visualizadas a partir da Figura 6 com a sua distribuição espacial e na Tabela 4 com a quantificação das classes na área do município.

As vertentes divergentes cobrem 48,50\% da área de estudo, enquanto as vertentes convergentes 51,50\%. De modo geral, a primeira caracteriza-se pelos processos de dispersão dos fluxos nas vertentes, à medida em que na segunda predominam os processos de concentração dos fluxos. Dessa forma, constitui-se em atributo do relevo importante na interpretação de áreas suscetíveis a ação erosiva linear na vertente, conjugado a dinâmica superficial condicionada pelo relevo visto em planta.

\begin{tabular}{ccc}
\hline Plano de Curvatura & Área em $\mathbf{k m}^{2}$ & Área em \% \\
\hline Divergente & 292,15 & 48,50 \\
Convergente & 310,23 & 51,50 \\
\hline
\end{tabular}

Tabela 4 Quantificação do plano de curvatura das vertentes do município de Unistalda - RS.

Fonte: Arquivo pessoal (2015)

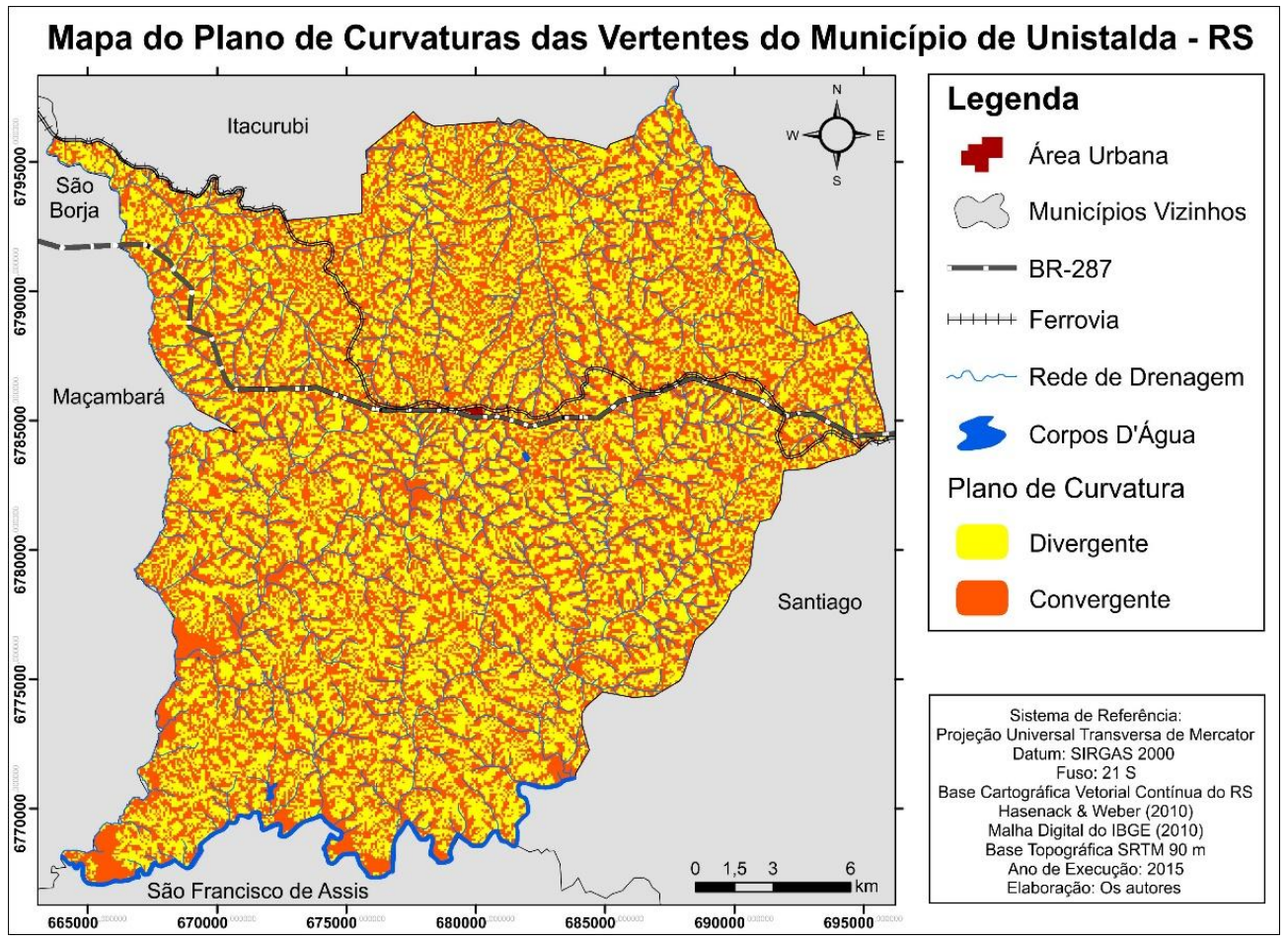

Figura 6. Mapa do plano de curvatura das vertentes com a rede de drenagem, principais vias de acesso e área urbana do município de Unistalda - RS. 
A partir da combinação do perfil e do plano de curvatura das vertentes para o município de Unistalda RS, conforme adaptado de Huggett (1975), analisou-se quatro classes, que representam as formas das vertentes (convexo-divergente, convexo-convergente, côncavo-divergente e côncavo-convergente), conforme podem ser visualizadas na Figura 7 e na Tabela 5, por meio da distribuição espacial e da quantificação das classes na área de estudo.

A classe de vertentes convexo-divergente cobre $31,59 \%$ de sua área, e ocorre com pontos de maior densidade associadas a áreas de relevo ondulado ou fortemente ondulado. Nas vertentes, respondem a porção de topo até seu segmento médio, caracterizando-se pelo aumento da energia de fluxo, com menor infiltração e máxima dispersão em função do plano divergente a medida em que as declividades do perfil da encosta são mais significativas.

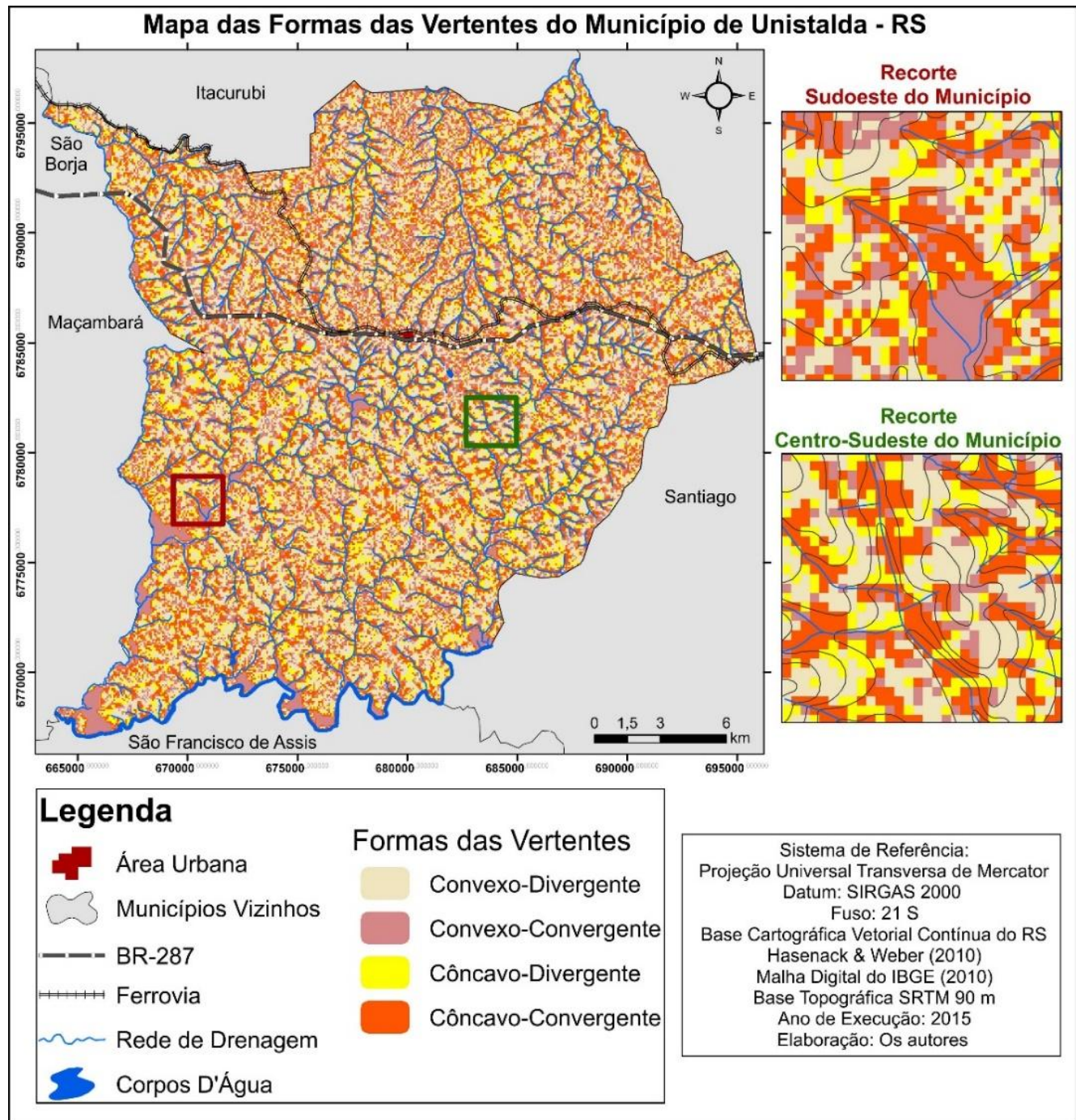

Figura 7. Mapa das formas das vertentes com a rede de drenagem, principais vias de acesso e área urbana do município de Unistalda - RS. 
A classe convexo-convergente cobre $18,43 \%$ da área do município e ocorre de maneira mais recorrente nas áreas de planície e leito fluvial das bacias hidrográficas. Nas vertentes correspondem as áreas superiores, relativas a seu terço superior até o segmento médio. Nestas áreas é onde ocorre o aumento da energia dos fluxos superficiais, com o predomínio dos mesmos sobre os processos de infiltração no terreno, como também o início da concentração dos escoamentos, devido ao plano de curvatura convergente. Atribuído a essas características, observa-se locais em que há o avanço de processos erosivos lineares.

A classe côncavo-divergente distribui-se em 16,91\% da área do município, nas vertentes corresponde ao segmento médio até a base das mesmas. Quando associadas a morrotes e cornijas, marcam sua porção inferior e nas áreas próximas as drenagens, nos sistemas fluviais, relacionam-se as áreas de planície com processos predominantes de dispersão dos fluxos associadas ao plano divergente e de maior velocidade dos escoamentos no ponto de inflexão do perfil convexo para côncavo, e com velocidades menores a medida em que a vertente se aproxima da sua base.

Por fim, a classe de curvatura côncavo-convergente cobre maior área, sendo 33,07\% do município, nos sistemas de drenagem associam-se ao leito dos segmentos de canais fluviais, sendo bem marcada esse tipo curvatura nos de menor hierarquia, como de primeira e segunda ordem. Nas vertentes corresponde ao segmento médio até a base, caracterizando-se pelo acúmulo e concentração máxima dos fluxos de escoamento nas vertentes. Nas porções Oeste, Sudoeste e Sul do município, junto ao Arroio Itu-mirim e afluentes de até $3^{0}$ ordem do Rio Itu, este tipo de curvatura está diretamente associado a ocorrência dos processos erosivos lineares conectados à rede drenagem com a formação de sulcos, ravinas e voçorocas.

\section{Relação dos Processos Erosivos Lineares com os Atributos Morfométricos do Relevo}

A partir da integração dos processos erosivos lineares com os atributos morfométricos do relevo no município de Unistalda - RS, identificou-se a relação que as áreas afetadas pela erosão dos solos possuem com as características do relevo. 
Com base na hipsometria (Figura 8), os processos de erosão linear localizam-se predominantemente em altitudes inferiores aos $200 \mathrm{~m}$, em especial, com a classe $150-200 \mathrm{~m}$ representando 78,72\%. A classe de altitudes $<150 \mathrm{~m}$ apresenta $3,39 \%$, as altitudes entre $200-250 \mathrm{~m}$ apresentam $17,82 \%$ e a classe de altitudes entre 250-300 m apenas 0,07\%.

Isso ocorre, em razão do limite de $200 \mathrm{~m}$ de altitude marcar uma área de transição entre compartimentos geomorfológicos de Depressão e de Planalto na área de estudo, e os processos de erosão localizarem-se predominantemente na área de relevo mais dissecada, associada a Depressão do Ibicuí, no táxon de Modelado de Patamares Residuais em Arenito (ROBAINA et al., 2010).

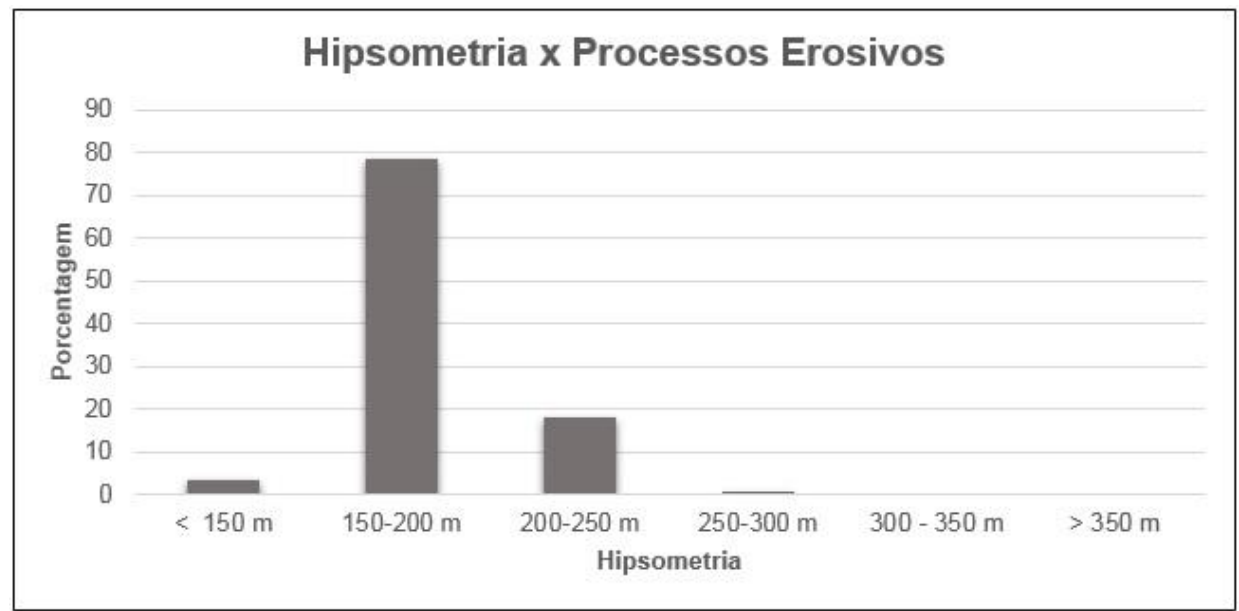

Figura 8. Gráfico que apresenta a relação das classes hipsométricas com a ocorrência de processos erosivos lineares no município de Unistalda - RS. Fonte: Arquivo pessoal (2015)

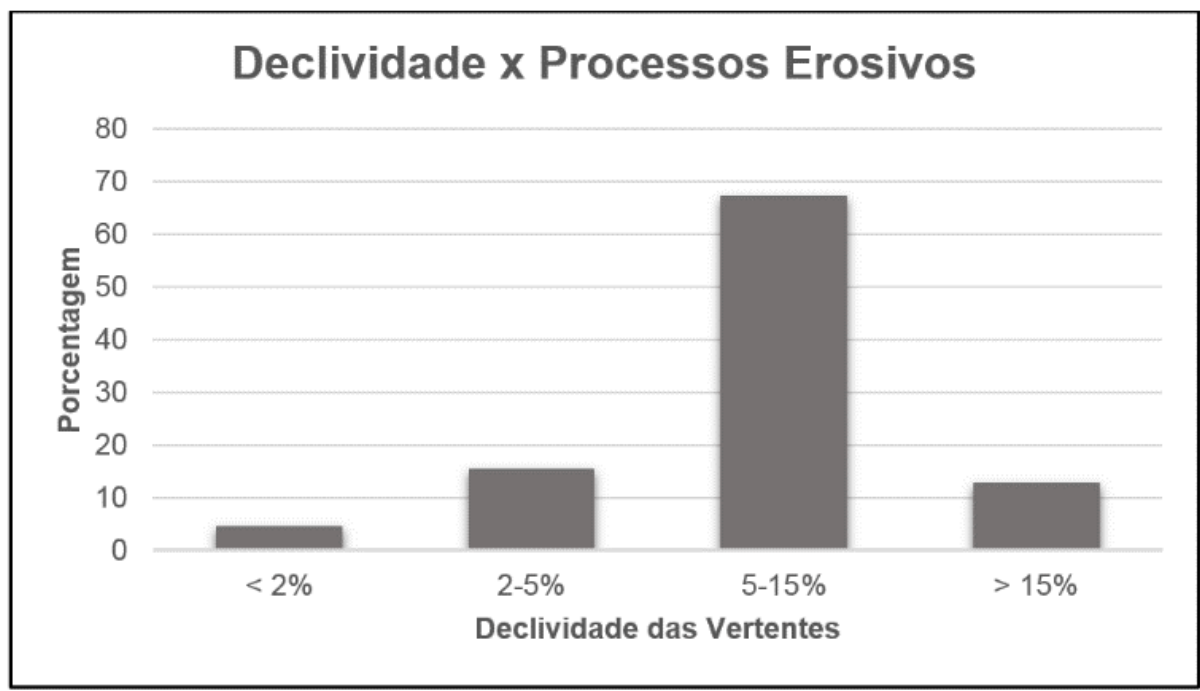

Figura 9. Gráfico que apresenta a relação das classes de declividade com a ocorrência de processos erosivos lineares no município de Unistalda - RS. Fonte: Arquivo pessoal (2015) 
Nos perfis de curvatura (Figura 10) identificou-se a predominância dos processos erosivos lineares em perfis côncavos, com $68,65 \%$, o que se associa as maiores energias dos fluxos do segmento médio em direção a base das vertentes, configurando dessa forma na maior recorrência dos processos erosivos neste tipo de curvatura. Por sua vez, os perfis convexos representam 31,35\%, relacionados em áreas de avanço dos processos erosivos lineares, onde passam ocorrer também solapamentos e movimentos de massa no terço superior das vertentes, em razão da erosão causada pelo escoamento subsuperficial.

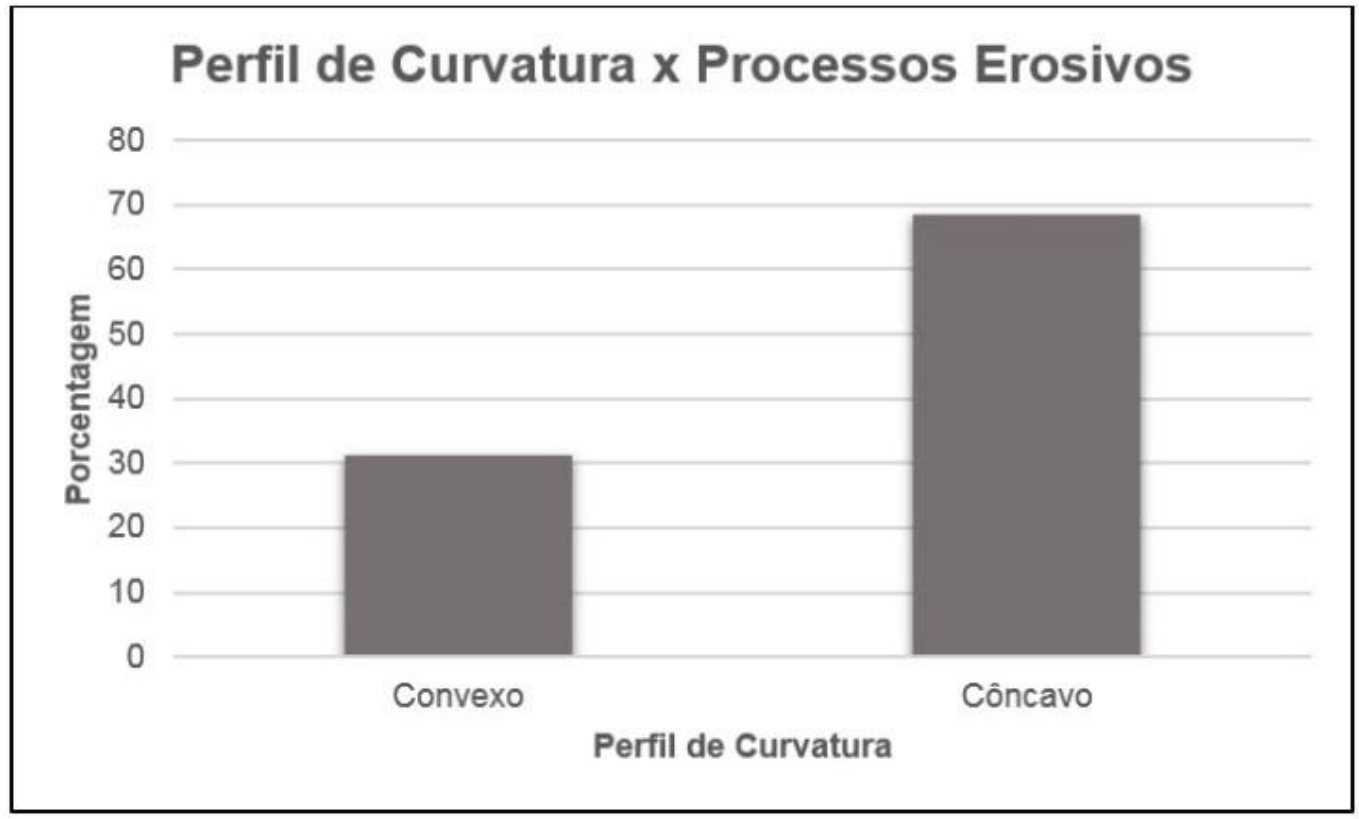

Figura 10. Gráfico que apresenta a relação das classes de perfil de curvatura com a ocorrência de processos erosivos lineares no município de Unistalda - RS. Fonte: Arquivo pessoal (2015)

Nos planos de curvatura (Figura 11) identificou-se a predominância dos processos erosivos lineares associados aos planos convergentes em $66,74 \%$. Isso ocorre, em função destes representarem os pontos onde há a máxima concentração dos fluxos nas vertentes e, por conseguinte, condicionando na maior ação erosiva pela concentração de água especialmente. As curvaturas divergentes, entretanto, apresentam-se em $33,26 \%$, embora não sejam áreas muito propícias para ocorrência dos processos erosivos, acabam associando-se aos mesmos, em decorrência, da integração das mesmas com outros parâmetros do relevo que podem prevalecer como, por exemplo, as declividades assim como aos demais elementos condicionantes. 


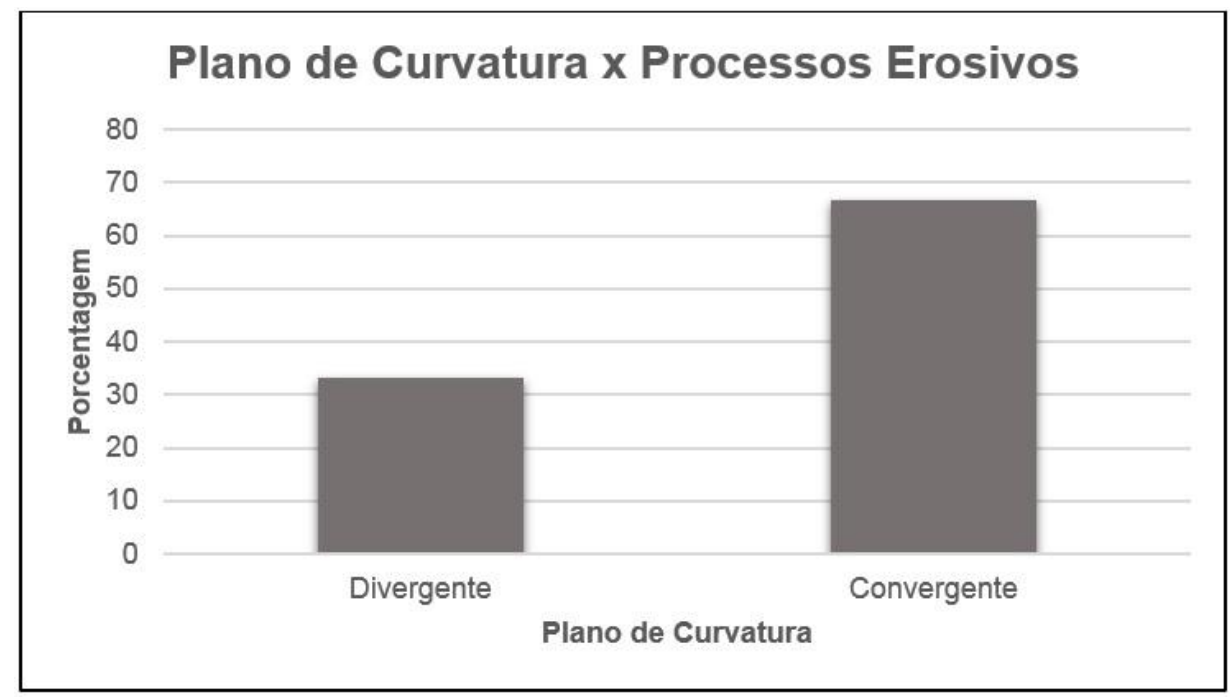

Figura 11. Gráfico que apresenta a relação das classes de plano de curvatura com a ocorrência de processos erosivos lineares no município de Unistalda - RS. Fonte: Arquivo pessoal (2015)

$\mathrm{Na}$ combinação dos perfis e planos de curvaturas das vertentes, resultando nas formas das vertentes (Gráfico 12) foi identificada uma classe predominante que se relaciona aos processos erosivos lineares na área de estudo, que são as curvaturas côncavo-convergentes, em 51,89\%.

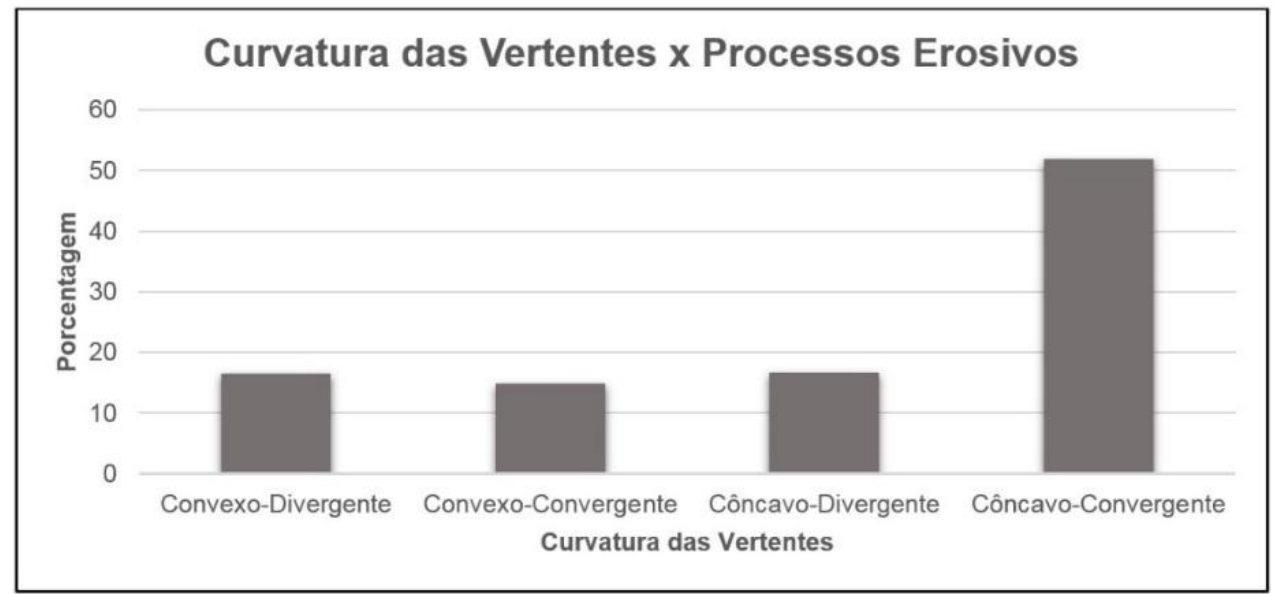

Figura 12. Gráfico que apresenta a relação das classes de formas das vertentes com a ocorrência de processos erosivos lineares no município de Unistalda - RS. Fonte: Arquivo pessoal (2015)

Nesta classe é onde há a maior concentração dos fluxos associadas ao plano convergente e de aumento das velocidades em conformidade ao perfil côncavo, configurando com o maior potencial erosivo condicionado pelo relevo. Já nas demais classes de vertentes, identificou-se distribuições equivalentes em $16,5 \%$ para curvaturas convexo-divergente, $14,85 \%$ para convexo-convergente e $16,76 \%$ para côncavo-divergente. 
Atribuído a essa análise foi possível identificar que há forte relação das áreas afetadas por processos erosivos lineares na área de estudo com as características do seu meio físico e neste caso, em especial, com os atributos do relevo que se apresentam como um fator condicionante a erosão dos solos.

Na Tabela 6 pode ser visualizado uma síntese das características morfométricas do relevo predominantes nas áreas afetadas por processos erosivos lineares no município de Unistalda - RS.

\begin{tabular}{cc}
\hline Parâmetros morfométricos do relevo & Classes que prevalecem na área de estudo \\
\hline Hipsometria & $150-200 \mathrm{~m}$ \\
Declividade & $5-15 \%$ \\
Perfil de Curvatura & Côncavo \\
Plano de Curvatura & Convergente \\
Forma da Vertente & Côncavo-Convergente \\
\hline
\end{tabular}

Tabela 6. Síntese das características morfométricas do relevo predominantes em áreas com processos erosivos lineares no município de Unistalda - RS. Fonte: Arquivo pessoal (2015)

Cabe mencionar que embora essas características apresentem relações com os processos de erosão linear, os mesmos também são condicionados aos demais aspectos da área de estudo como, por exemplo, a precipitação, substrato litológico, solos, tipos de uso e ocupação da terra, cobertura dos solos e entre outros fatores.

Isso se corrobora na medida em que nem todas as áreas com as características do relevo identificadas como mais suscetíveis a sofrerem com os processos erosivos, de fato apresentarem solos degradados, mas sim, apenas nos sistemas de drenagem delimitados pelo Arroio Itu-Mirim e em afluentes de até $3^{\text {o }}$ ordem do Rio Itu, a Oeste, Sudoeste e Sul do município, que também conjugam outros fatores condicionantes aos processos de erosão linear dos solos.

Sendo assim, o estudo permitiu identificar a relação que o relevo confere aos processos erosivos na área de estudo, mas apontando a relevância das bacias hidrográficas nesta relação na qual se apreciam de forma sistêmica, servindo conforme apresentam Botelho e Silva (2014) como unidades básicas para as análises ambientais.

\section{CONSIDERAÇÕES FINAIS}


Neste trabalho foi realizado o mapeamento dos processos erosivos lineares e do relevo através de atributos morfométricos para o município de Unistalda - RS, permitindo com a integração dessas informações, identificar quais características do relevo são mais comuns em áreas afetadas pela erosão linear dos solos na área de estudo.

Atribuído a isso, identificou-se como mais recorrentes áreas com altitudes inferiores a $200 \mathrm{~m}$, em especial na classe hipsométrica de 150-200 m, declividades em geral superiores a 5\%, com a classe 5$15 \%$, perfis de curvatura côncavos, planos de curvatura convergentes e formas de vertente côncavoconvergentes.

Através da utilização de técnicas de geoprocessamento, integradas ao ferramental do SIG (Sistema de Informação Geográfica) e com imagens de satélite ópticas e de RADAR SRTM, foi possível o mapeamento das áreas afetadas por processos erosivos lineares, como também a modelagem do relevo, com resultados satisfatórios que corroboraram com as informações validadas durante os trabalhos de campo.

Frente a isso, este trabalho visou contribuir com a temática a partir da indicação de áreas mais suscetíveis aos processos de erosão linear dos solos com base nas características morfométricas do relevo no município de Unistalda - RS. Desse modo, servindo como informação primária para estudos mais avançados na área de estudo, seja com a temática dos processos erosivos lineares, assim como, para mapeamentos geomorfológicos e/ou zoneamentos geoambientais.

\section{AGRADECIMENTOS}

Agradecimento aos órgãos de fomento à pesquisa CAPES e CNPQ pela concessão de bolsas e de apoio financeiro.

\section{REFERÊNCIAS}

AB'SABER, A. A revanche dos Ventos: Destruição de solos areníticos e formação de areais na Campanha Gaúcha. Revista Ciência \& Ambiente, n.11, Santa Maria: Editora da UFSM, 104p. p. 7-31, 1995. 
BOTELHO, R. G. M.; SILVA, A. S. Bacia hidrográfica e qualidade ambiental. In: VITTE, A. C.; GUERRA, A. J. T. (Org.). Reflexões sobre a geografia física no Brasil. 7 ed. Rio de Janeiro: Bertrand Brasil, 2014, 282p. p. 153-192.

CAStro, U. N.; NEVES, S. R. A.; SIlvA, L. F. T. C.; MENDES, S. P.; GUERRA, A. J. T. Mapeamento de Feições Erosivas e Cicatrizes de Escorregamento por Unidades de Relevo na Sub-Bacia do Rio Sana (Macaé - RJ). Revista de Geografia, Recife: UFPE - DCG/NAPA, v. especial, VIII SINAGEO, n. 3, p. 19-33. 2010.

CERRI, L. E. S.; SILVA, J. A. F.; SANTOS, P. H. P. Erosão do solo: aspectos conceituais. Geociências, Guarulhos, v.2, n.3, p. 92-98, 1997.

DE NARDIN, D. Zoneamento geoambiental no oeste do Rio Grande do Sul: um estudo em bacias hidrográficas. 230 f. Dissertação (Mestrado em Geografia). Programa de Pós-Graduação em Geografia, Universidade Federal do Rio Grande do Sul, 2009.

FERREIRA, M. C. Iniciação à análise geoespacial: teoria, técnicas e exemplos para geoprocessamento. 1 ed. São Paulo: Editora Unesp, 2014. 343p.

GUERRA, A. J. T. Degradação dos solos - conceitos e temas. In: GUERRA, A. J. T.; JORGE, M. C. O. (Org.). Degradação dos solos no Brasil. Rio de Janeiro: Bertrand, 2014. 15-50p.

HUGGETT, R. J. Soil Landscape Systems: A model of soil genesis. Geoderma, v. 13, p. 01-22, 1975.

INSTITUTO DE PESQUISAS TECNOLÓGICAS (IPT). Mapeamento Geomorfológico do Estado de São Paulo. v. 2. São Paulo, Escala 1:500.000, 1981. 130 p.

Robaina, L. E. S., Trentin, R., BAZZAN, T., RECKZIEGEL, E. W., VERDUM, R., DE NARDIN, D. Compartimentação Geomorfológica da Bacia Hidrográfica do Ibicuí, Rio Grande do Sul, Brasil: Proposta de Classificação. Revista Brasileira de Geomorfologia, São Paulo, v.11, n.2, p. 11-23, 2010.

SANTOS, E. E.; FARIA, A. L. L. Mapeamento e monitoramento de processos erosivos a partir de imagens Ikonos: Um estudo de caso da área urbana do Município de Queluzito (MG). In: Simpósio Brasileiro de Sensoriamento Remoto - SBSR, 15., 2011, Curitiba, Anais..., Curitiba, PR, INPE, 2011, p. 5716-5721.

SILVEIRA, P. R. M.; SILVEIRA, C. T.; OKA-FIORI, C. Emprego de Técnicas de Inferência Espacial para Identificação de Unidades de Relevo Apoiado em Atributos Topográficos e Árvore de Decisão. Revista Brasileira de Geomorfologia, São Paulo, v.15, n.1, p. 87-101, 2014.

SOUTO, J. J. P. Deserto, uma ameaça? Estudos dos núcleos de desertificação na fronteira sudoeste do Rio Grande do Sul. Porto Alegre: Secretaria da Agricultura - Diretoria Geral, 1985. 172p.

SOUZA, A. C. Análise dos areais da Bacia Hidrográfica do Arroio Puitã, Oeste do RS, através do mapeamento multitemporal no período de 1984 a 2014. 141 f. Dissertação (Mestrado em Geografia). Programa de Pós-Graduação em Geografia, Universidade Federal de Santa Maria, 2015.

STRAHLER, A. N. Hypsometric (area-altitude) analysis and erosional topography. Geological Society of America Bulletin, v.63, p. 1117-1142, 1952 .

SUERTEGARAY, D. M. A. Deserto grande do sul: controvérsia. 2 ed., Porto Alegre: Editora da Universidade Federal do Rio Grande do Sul, 1998. 109p.

SUERTEgARAY, D. M. A. A Trajetória da Natureza um Estudo Geomorfológico sob os Areais de Quaraí/RS. Tese (Doutorado). Faculdade de Filosofia, Letras e Ciências Humanas, Universidade de São Paulo, 1987. 
SUERTEGaraY, D. M. A.; GUASSELli, L. \& VERDUM, R. (Org.). Atlas de Arenização: Sudoeste do Rio Grande do Sul. v.1. Porto Alegre: Secretaria da Coordenação e Planejamento, 2001.

SUERTEgarAY, D. M. A.; SIlvA, L. A. P.; GUASSELI, L. A. (Org.). Arenização: Natureza Socializada. Porto Alegre: Compasso Lugar-Cultura, Imprensa Livre, 2012. 600p.

TREnTIN, R. Mapeamento Geomorfológico e Caracterização Geoambiental da Bacia Hidrográfica do Rio Itu - Oeste do Rio Grande do Sul - Brasil. 215 f. Tese (Doutorado em Geografia). Programa de Pós-Graduação em Geografia, Universidade Federal do Paraná, 2011.

VALERIANO, M. M. Dados Topográficos. In: FLOREnZANO. T. G. (Org.) Geomorfologia: conceitos e tecnologias atuais. São Paulo: Oficina de Textos, 2008. 318p. p. 72-104.

VERDUM, R. Approche Géographique dês "Deserts" Dans lês Communes de São Francisco de Assis et Manuel Viana, Etat du Rio Grande do Sul, Bresil. 211 f. Tese (Doutorado em Geografia) - UFR de Géographie/Aménagent, Université de Toulouse Lê Mirail, Toulouse, 1997. 